\title{
Factor Analysis on the Fluctuation of China's Cotton Import-Based on the CMS Model
}

\author{
Tai-Xiang WANG ${ }^{1, a,{ }^{*}}$, Si-Yu ZHANG ${ }^{2, b}$, Jie ZHANG ${ }^{3, c}$, Hong-Hui ZHU ${ }^{4, d}$ \\ ${ }^{1,2,3,4}$ Economics and Management School, Shihezi University, Shihezi, Xinjiang, China, 832000 \\ awtx8007@126.com, b1647752630@qq.com, '859053202@qq.com, d361285098@qq.com \\ ${ }^{*}$ Corresponding author
}

Keywords: Fluctuation of importation on cotton, CMS model, Imported gravity, Import structure.

\begin{abstract}
This article analyses the causes of fluctuations of the cotton import trade in China, using the modified CMS model with the date between 1994 and 2012 from the datebase of UN Comtrade. The results show that the fluctuations of the import trade on cotton in china is effected by domestic imports of gravity and import structure. The problems are caused by import structure of gravity on cotton and the disorderly change in high cost of cotton production, imperfect circulation system and market information.
\end{abstract}

\section{Introduction}

In recent years, with the rapid development of China's textile and garment industry, the demand of cotton raw and its processed products continues to increase, coupled with poor difference in domestic price of cotton, the scale of China's cotton imports rapidly expanding. As shown in Figure 1, cotton import trade [11] has been at low levels until China's accession to WTO,after then cotton import trade has a substantial growth, especially since the 2008 global financial crisis, the average annual growth rate of total cotton imports reached $25.86 \%$, in 2012 China's cotton imports accounting for $36.29 \%$ of the world's total cotton imports. Undoubtedly, in the context of economic globalization, the continued growth of cotton imports, to a large extent, ensure the domestic demand for cotton, but also affected the earnings of domestic cotton growers and the enthusiasm for cotton production, further pushed up stocks of domestic cotton, reduced the interest space of cotton textile enterprises, the import trade of cotton has become the focus attention of public.

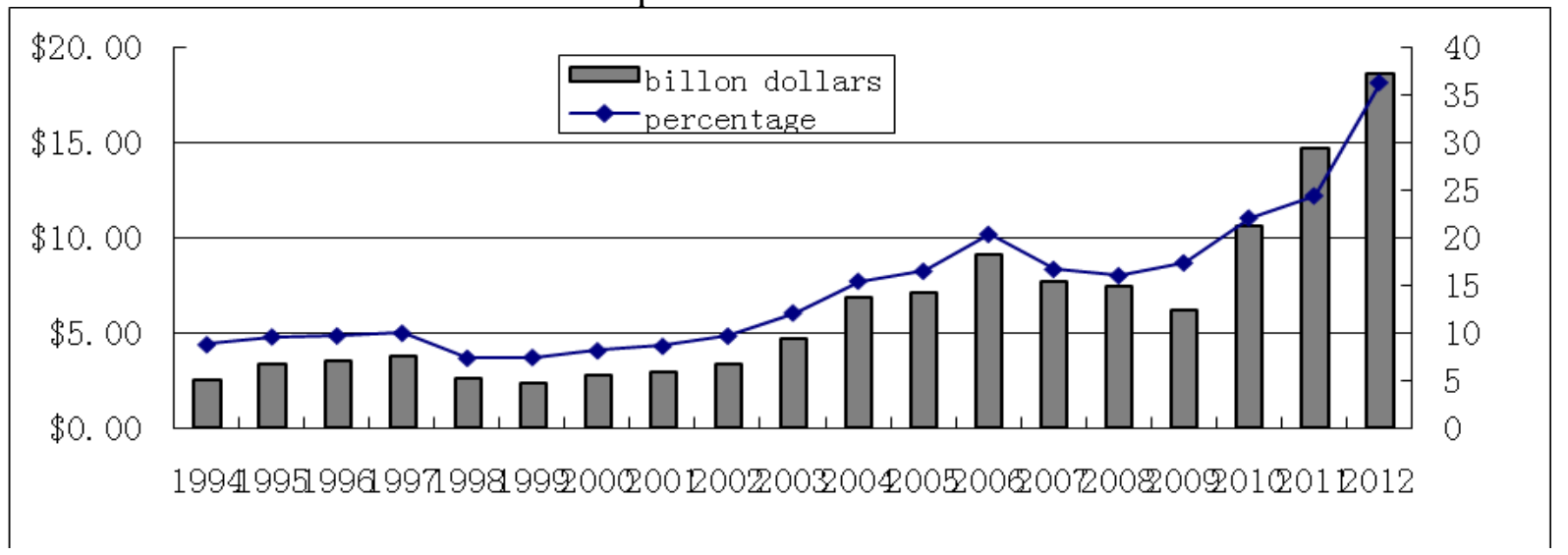

Source: United Nations Statistics Division website

Figure 1 Chinese cotton imports trade situation over the years

Over the years, many scholars pay close attention to research the problem of cotton imports. Zhu Zaiqing, Liu Minzhi's (2012) study showed, China's cotton market is highly concentrated on the source of imports, and cotton import sources have gradually focused on the country with import price elasticity advantage, which saves cost of China's cotton import and be beneficial to respond to prices risk; Song Juguo, Liu Yizhuo (2010) using GTAP model to simulate the impact of imports on China's cotton industry, considered that the competitive power of China's cotton industry decreased 
significantly, the import dependency rised, cotton-quota tariff rate will significantly reduce imports of cotton and is conducive to the development of China's cotton industry. Lu Qiuyan (2008) analyzed the economic effects of tariff concession program according to different cuts produced by ATPSM model, considered that the reduction of cotton import tariff improve social welfare, but harm the interests of cotton farmers in China. Lu Feng's (2006) study showed that there is a significant inversely relationship between the changes of number in net exports of cotton trade and the changes of international cotton price, the low trade efficiency and the inventory fluctuations of domestic cotton lead to excessive fluctuations in net exports of cotton, the price-intervention policy under monopoly purchase is the ultimate institutional roots of this phenomenon. Li Qin and Sun Liangyuan's (2005) study showed that cotton imports, stocks and prices reinforce each other .

From the available literature, the research objects on cotton imports mainly targeted on raw cotton, containing none different levels of cotton yarn or cotton woven fabrics, etc., which can not fully reflect the trading situation of China's cotton imports. Moreover, the existing research on cotton import trade most focus on measuring economic benefit of different tariffs or quotas policy, lacking of the analysis of influence factor and origin cause of domestic and international cotton price fluctuations. In this paper, the use of HS1992 cotton trade classification data aims to use CMS model to explore the import trade fluctuation of cotton and its causes in China since 1994, provide the basis for the adjustment and formulation of industrial policy of cotton the adjustment and formulation of industrial policy of cotton

\section{Model and Data Sources}

\section{Model Selection}

In this paper, the classical CMS model based on Jempa, in reference to domestic scholars (Shuai Chuanmin, Cheng Guoqiang, Zhang Jinlong 2003, Jiang Yan 2008, Ying Ruiyao, Zhou Li) structure based on CMS model, in view of our country cotton import trade fluctuations, CMS model is put forward to the corresponding.

This CMS model does two level decomposition on import trade fluctuation of China's cotton, as the following formula:

The first level decomposition formula

$$
\Delta m=\sum_{i} \sum_{j} S^{0} \Delta M_{i j}+\sum_{i} \sum_{j} M_{i j}^{0} \Delta S_{i j}+\sum_{i} \sum_{j} \Delta S_{i j} \Delta M_{i j}
$$

Structural effect Gravity effect Second-order effect

The second level decomposition formula

$$
\Delta \mathrm{m}=S^{0} \Delta M+\left[\sum_{i} \sum_{j} S_{i j}^{0} \Delta M_{i j}-\sum_{i} S_{i}^{0} \Delta M_{i}\right]+\left[\sum_{i} \sum_{j} S_{i j}^{0} \Delta M_{i j}-\sum_{j} S_{j}^{0} \Delta M_{j}\right]
$$

Growth effect The market effect Goods effect

$+\left[\left[\sum_{i} S_{i}^{0} \Delta M_{i}-S^{0} \Delta M\right]-\left[\sum_{i} \sum_{j} S_{i j}^{0} \Delta M_{i j}-\sum_{j} S_{j}^{0} \Delta M_{j}\right]\right]+\Delta S M^{0}$

Structure interaction effect The overall gravity effect

$+\left[\sum_{i} \sum_{j} \Delta S_{i j} M_{i j}^{0}-\Delta S M^{0}\right]+\left(\frac{M^{1}}{M^{0}}-1\right) \sum_{i} \sum_{j} \Delta S_{i j} M_{i j}^{0}$

Specific gravity effect Pure second-order effect

$+\left[\sum_{i} \sum_{j} \Delta S_{i j} \Delta M_{i j}-\left(\frac{M^{1}}{M^{0}}-1\right) \sum_{i} \sum_{j} \Delta S_{i j} M_{i j}^{0}\right]$

Dynamic residual effect 
In this model, the subscript $\mathrm{i}$ represents the types of goods, $\mathrm{j}$ representatives of countries and regions; superscript 0 represents the beginning of the year, represents the end of the year. $\triangle$ indicates the changes in value by comparing the final with the initial (the final increment relative to the beginning of the period), $m$ represents China's total imports in cotton, $S$ for the import of cotton in China occupies in the world cotton import market share, $S_{i}$ says China's total imports of class I of cotton in world market share on the total amount of the cotton import, $S_{j}$ says China's total imports of $\mathrm{J}$ cotton in the world to the proportion of the country's total imports of cotton, $\mathrm{S}_{\mathrm{ij}}$ says China's total imports from the country $\mathbf{J}$ of class I cotton accounted for the total world import. M represents the total world imports of cotton, $\mathrm{M}_{\mathrm{i}}$ says the total world imports at the cotton of class $\mathrm{I}, \mathrm{M}_{\mathrm{j}}$ says the total world imports of $\mathbf{J}$ in cotton, $\mathbf{M}_{\mathrm{ij}}$ says the total world imports from country $\mathbf{J}$ of class I cotton.

\section{Data Description}

In this paper, data are all from UN comtrade commodity trade database founded by the United Nations Statistics Division commodity trade database. Finishing the goods in accordance with the classification method of HS(Harmonized Commodity Description And Coding System) 1992, when analyzing the specific cotton items subject, the 52 code will be refine for 12 A 4 items subject coding, detailed in Table 2. Because in the course of the study, founding that 5202 and 5211 kinds of commodity data is incomplete, and they are less than $3 \%$ share of the total in 52 categories, considering the accuracy and availability considerations of the date, this paper excluding these two classification of goods, analyzes 10 classification of the remaining cotton products.

Through the analysis of the main import source country of cotton products, model introduced in 8 countries and regions as cotton import trade body, namely the America, Australia, India, Pakistan, Uzbekistan, Brazil, Egypt, and other countries and regions, a total of eight countries and regions. In the calculation of CMS model, the author choose the time span of 1994-2012, and divided into 5 stages according to the trade volume of imports of China's cotton changes, namely, 1994-1998 --- the stage of steady growth, 1998-2001 --- the stage of Asian financial crisis recession, 2001-2006 --- the stage of growth period after accession to the WTO, 2006-2009 --- the stage of rapid recession of global economic crisis , and 2009- 2012 --- the stage of global economic recovery growth.

\section{Analysis of the Causes of Chinese Cotton Import Trade Fluctuation}

\section{The Overall Effect Analysis}

Overall, 1994-2012 China's cotton imports increased from $\$ 2.526$ billion to $\$ 18.681$ billion, increasing of $\$ 16.155$ billion, with an average annual growth rate of $15 \%$. In the first layer factor decomposition, the second-order effect is the main influent factors, interaction of gravity and structure brings the China's cotton imports increased by $\$ 5.824$ billion, the contribution rate was $41.95 \%$. The gravity effect are second major factors influencing our country's cotton import growth, imports of gravity change caused by China's cotton imports increased by $\$ 5.658$ billion, the contribution rate was $40.75 \%$. Next is the structure effect, changes in world cotton import demand caused China's cotton imports increased by 2.401 billion yuan, the contribution rate was $17.29 \%$.

In second level of decomposed factors, what mainly caused by the factors of China's cotton import trade growth fast in 1994-2012 is the whole gravitational effects, dynamic structure of residual, pure second-order effect, growth effect and structure interaction effect in turn, but commercial effect, market effect and specific gravity effect is reduced the import of cotton in china. From the submissive factors, 1994-2012 growth of China's cotton imports increased firstly originated from China's overall export gravity increasing on the world cotton market, China's cotton imports accounted for the proportion of total world imports increased from 8.74\% in 1994 to $36.29 \%$ in 2012, increasing of 27.55 percentage points; Secondly, great changes have taken place in the structure of import of cotton in China, the proportion that 5201 and 5203 class of cotton products increased from $26.20 \%$ in 1994 to $63.19 \%$ in 2012 , increasing of 36.99 percentage points; at the same time, the structure of world cotton import also have great change, the proportion that 5201 and 5203 class of cotton products increased from $27 \%$ in 1994 to $39 \%$ in 2012, increasing of 12 percentage points; once again, market gravity of China to the whole world cotton imports continues to increase, China's cotton imports 
accounted for the proportion of total world imports increased from $8.74 \%$ in 1994 to $36.29 \%$ in 2012 , increasing of 27.55 percentage points; Fourthly, in the origin country of China's cotton imports, the United States has been a relatively stable one, in 1994, China's total imports from the USA accounted for the proportion of China's total cotton imports $22.17 \%$, while in 2012 it was $20.49 \%$, but China's total imports from India accounted for the proportion of total imports of cotton increased from $0.62 \%$ in 1994 to $21.92 \%$ in 2012, increasing of 21.30 percentage points. India is the country which has the biggest import growth among China's cotton import origin countries

Lastly, interaction effect of structure shows that the market structure of China's cotton import as well as China's cotton import trade fluctuations, and commodity structure are closely linked.

Table 1 The decomposition results of factor on China's cotton import trade fluctuation based on CMS model (Unit: 100 million USD)

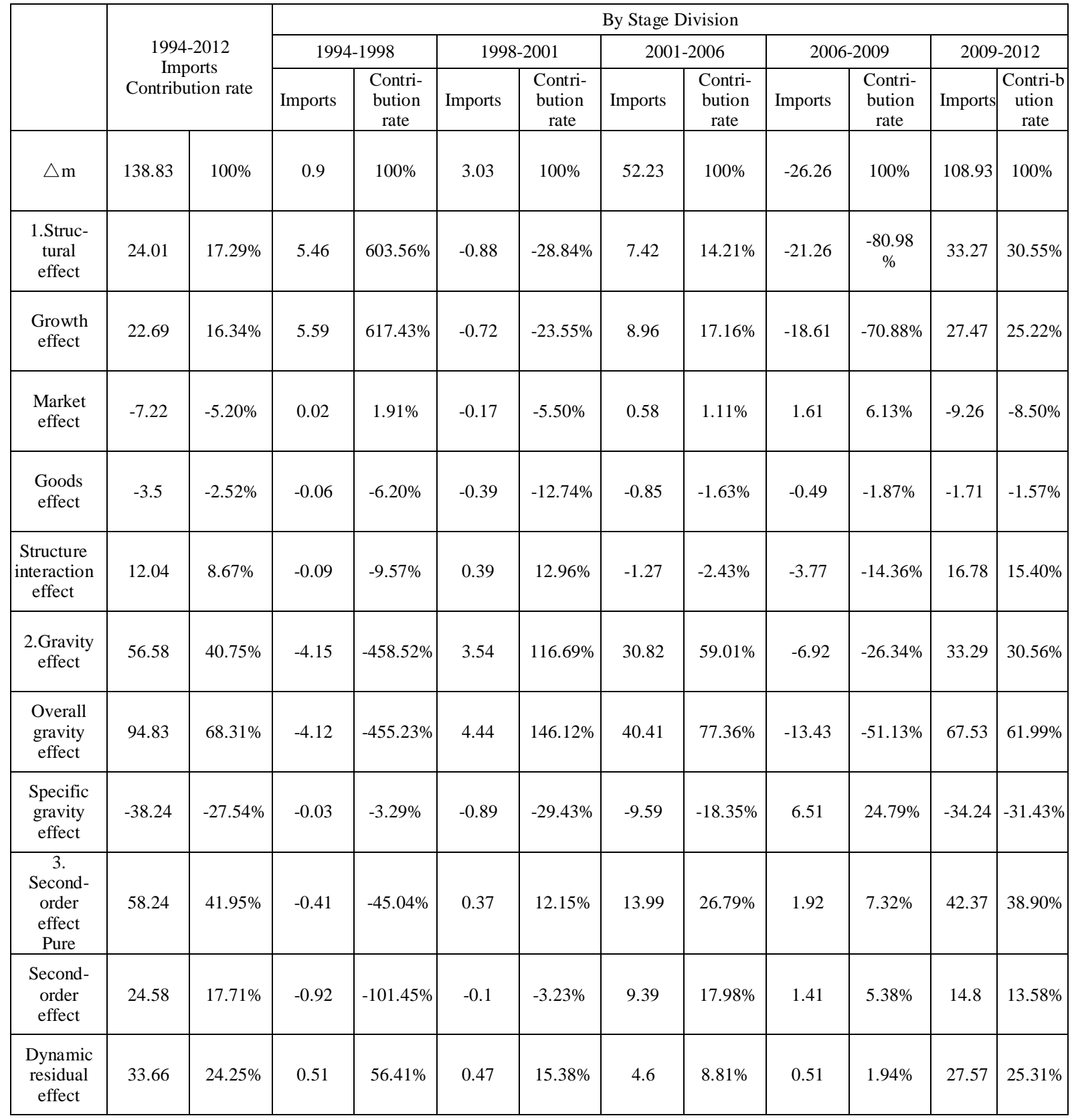

\section{Analysis of the Factors Affecting Cotton Import Growth in China}

Structural effect and the growth of China's cotton import. The increase demand for imports of the world cotton market is an important factor to stimulate China's imports of cotton. From 1994 to 1998 , the whole world cotton imports increased from $\$ 2.89$ billion to $\$ 3.53$ billion, the international market demand for imports has increased by $\$ 0.64$ billion in 4 years, an increase of $22.13 \%$. While in 
2009-2012, the total world cotton imports increased from \$ 3.56 billion to $\$ 5.15$ billion, the international cotton market demand for imports has increased by $\$ 1.58$ billion, an increase of $44.45 \%$. It is due to the increase in the international cotton market import demand in these two stages, that lead to imports at the first stage and the fifth stage is respectively increased by $\$ 5.46$ billion and $\$ 3.327$ billion, even when China's cotton imports share remains unchanged in the international market. The surge demand in world cotton import is mainly because of the development of the textile industry, improve the processing of total 2012 textile fiber in China accounted for the proportion of the world to about $55 \%$, exports account for about $36 \%$ of global proportion. From the influence of the contribution size factors, increasing world market demand effect of the first stage is the leading factor for our country cotton import growth, contribution rate it does to China's cotton import growth is as high as $603.56 \%$,in the fifth stage of China's cotton imports growth contribution rate is $30.55 \%$.

Gravity effect and the growth of China's cotton import. In the second stage and the third stage, the effection of gravity is the main factors lead to our country cotton import growth, the contribution rate of growth in imports of cotton reached $116.69 \%$ and $59.01 \%$ respectively, which is the second factor. The effection of gravity show that the species' structure of China's cotton imports can adapt to the change of demand of domestic cotton commodity structure very well. From the commodity structure of world cotton products can be found that what world cotton market needs mostly is the 5201 and 5205 class of cotton products in the 2012, their import proportion of the world's total imports respectively accounted for $38.51 \%$ and $20.75 \%$. from the history of the changes of world's cotton imports, the top four growth rate of categories were 5203, 5201, 5205 and 5206 class of cotton products. Control the commodity structure of China's cotton imports, imports in 2012 the proportion of 4 class of cotton before the product is highest is 5201, 5205, 5209, 5210 class of imported cotton, cotton varieties of products such as increased 5201 and 5205 class exactly in line with the international market demand. Secondly, the costs of china's cotton planting continue to rise, the price gap between domestic and international is widening, and the domestic textile enterprises' demand for raw cotton imports have risen in recent years. Thus, the overall effect of gravity is positive, and promoted the increase in imports of China's cotton products.

Second-order effect and the growth of China's cotton import. Second-order effect of China's cotton imports increased from $-40.04 \%$ at the first stage to the fifth stage of the $38.90 \%$. In which the pure second-order effect from the first stage of $-101.45 \%$ increased to the fifth stage of $13.58 \%$, indicate that the change in China's cotton imports of gravity keep pace with the world cotton import demand, cotton import gravity fluctuates with the world economy ups and downs; the dynamic structure of residuals in five stages are all positive, shows that import gravity of cotton in China is with the rapid growth of market share in rapid growth's world cotton imports, Brazil is the world's emerging cotton exporter through the analysis in recent years by further research. Brazil's cotton imports of the world in 2009 is about $\$ 817$ million increased to $\$ 2.628$ billion in 2012, an increase of more than 3 times, China to Brazil's cotton imports grew from \$71 million in 2009 to $\$ 816$ million in 2012 , an increase of 8 times.

\section{Analysis of the Factors Affecting the Degradation of China's Imports of Cotton}

The fourth stage (2006-2009) of China's cotton imports fell by $\$ 2.626$ billion, the main reasons of the decline has two aspects: Firstly, the world market demand fell sharply, the world market cotton imports fell by $\$ 9.15$ billion over the same period, because of the structure effect of China's cotton imports to the implications of the decline up to $80.98 \%$, causing cotton's import absolutely reduct in the amount of $\$ 2.126$ billion; Secondly, China's cotton imports gravity glides substantially, the decline in gravitational effect result in cotton imports dropped by $¥ 692$ million, the impact reached $26.34 \%$. Due to the impact of the global economic crisis, the world cotton imports decreased from $\$ 44.791$ billion in 2006 to $\$ 35.64$ billion in $2009,20.43 \%$ less than the market demand in 2006 . The data result reflects the economic conditions at that time. Affected by the global economic crisis, the domestic textile and garment industry to survive the difficulties. According to the survey, at the time of global economic crisis, the income of national scale textile and garment enterprises reduce about $¥ 160$ billion, The average profit of $2 / 3$ among 45 thousand enterprises has less than $0.7 \%$, in which 
6420 enterprises loss amounted of $¥ 13.1$ billion, reduce textile enterprise benefit is one of the main reasons for decline in cotton imports.

\section{Summary}

This paper make an empirical study on the cotton import of china by CMS model, using the trade data from United Nations Statistics Department. The results showed that: in 1994-2012, China's import of cotton growth was mainly from the second-order effect, that is to say the combined action of cotton import structure and gravity have achieved rapidly growth of imports of cotton; Secondly, the gravity effect is the second major factor affecting China's cotton import growth, the rapid development of the textile industry and the different price between domestic and international make our country strong gravity on cotton primary products. At the same time we found that China's cotton imports gravity fluctuate with the world economic situation ups and downs, the direction of gravity changes and changes of the whole world cotton import demand is consistent; In addition, changes in world cotton's import demand has brought substantial growth in China's cotton imports.

\section{References}

[1] TyszynskiH.World Trade in Manufactured Commodities.1899-1950.The Machester School of Economic and Social Studies.Vol.9(1951)222-304.

[2] Jempa, C.J.Extensions and application possibilities of the constant market analysis: the case of the developing countries' exports.University of Groningen. 1986.

[3] Zhu Zaiqing, Liu Minzhi.Research on China's cotton import market concentration and price elasticity.Journal of International Trade. 2 (2012)33-42.

[4] Song Juguo, Liu Yizhuo.Analysis of import impact on China's cotton industry.Journal of Agrotechnical. 5 (2010)91-97.

[5] Lu Qiuyan.Partial equilibrium analysis of effects that different tariff concessions scheme does on the import of agricultural products in China -- in the case of cotton. Journal of International Trade . 9 (2008)8-13.

[6] Lu Feng.Comparative advantage structure and open type cotton industry development --Chinese cotton trade policy at the crossroads of choice. Management World. 11 (2006)59-68.

[7] Li Qin,Sun Liangyuan.The interactive relationship between the price of cotton, imported and inventory. Chinese Rural Economy. 7(2005)71-77.

[8] Shuai Chuanmin, Cheng Guoqiang, Zhang Jinlong.Estimation of the international competitiveness of China agricultural products. Management World. 1 (2003)97-103.

[9] Zhou Li, Ying Ruiyao, Jiang Yan.Study on the fluctuation of China's wine imports trade -- Based on CMS model factor decomposition.Journal of Agrotechnical. 2 (2008)25-30.

[10] Tan Yanwen, Guan Jianbo.Macroeconomic factors, consumer demand, market information and the cotton market price volatility.Journal of Agrotechnical. 8 (2013)12-22.

[11] Classification according to the HS1992 statistical standards, trade of cotton varieties of a total of 12 (range, HS code 5201-5212) involves not only the seed cotton and lint, also contains cotton yarn and cotton woven fabrics of different cotton content. This paper refers to the cotton involving 12 species covered HS1992 classification.

[12] The data for all of the total imports of cotton goods.

[13] China Cotton Network, http://www.cncotton.com/ 